\title{
UMA ABORDAGEM SOBRE OS DIREITOS POLÍTICOS DOS INDÍGENAS NO MARCO DAS NORMATIVAS INTERNACIONAL E BRASILEIRA
}

\author{
A brief approach about the political rights of indigenous people in the \\ international and Brazilian legal framework.
}

Ana Claudia Santano

Resumo: Ainda que tenham sido vítimas de diversos atentados contra a sua existência, os povos autóctones seguem fazendo parte da pluralidade brasileira, tendo direitos e deveres assegurados pela Constituição de 1988. Dentre esses direitos estão os políticos, vitais para dar voz a esses grupos. No entanto, embora esse tema tenha sido tratado nos âmbitos do Direito Constitucional e nos Direitos Humanos, o Direito Eleitoral ainda carece de estudos específicos, na contramão do interesse crescente sobre o assunto. Assim, este breve ensaio tem como objetivo trazer um apanhado geral dos direitos políticos dos autóctones, partindo do disposto na Convenção 169 da OIT, para logo acrescentar as normas constantes nos sistemas onusiano e interamericano. Após, serão expostas as regras brasileiras tanto no âmbito constitucional quanto na legislação ordinária, trazendo algumas impressões vindas desde a aplicação dessas regras pela Justiça Eleitoral. Essa análise de regramento virá acompanhada de algumas decisões judiciais que demonstram como isso vem ocorrendo nos últimos anos proferidas tanto na esfera interamericana quanto pelo Poder Judiciário brasileiro.

Palavras-chave: Povos indígenas. Direitos políticos. Convenção 169 OIT. Justiça Eleitoral. Sistema Interamericano de Direitos Humanos.

\begin{abstract}
The indigenous people from Brazil had suffered many threads against their existence since long time ago. However, they still are part of Brazilian plurality and have lots of rights guaranteed by the 1988 Constitution. One of these rights is the political one, which gives them voice to participate actively in the democracy. Although this issue had been analyzed in the Constitutional Law and Human Rights field, there is a lack of studies from the Electoral Law point of view, in the wrong direction of the growing interest about this theme. Considering this, this brief essay aims to bring the political rights of indigenous people examined through the international and Brazilian legal framework, adding to the analysis some decisions of the Electoral Supreme Court and the Inter-American Human Rights Court to show how these rules are applied.
\end{abstract}

Keywords: Indigenous people; political rights; Convention 169 ILO; Electoral Judicial Authority; Inter-American System of Human Rights. 


\section{Introdução}

No Brasil, segundo o censo do IBGE realizado em 2010, há 817.963 indígenas nos 255 povos catalogados, sendo este um número aproximado. Desses, 315.180 encontram-se em áreas urbanas, e 502.783 em perímetros rurais ${ }^{1}$. Embora não existam dados consolidados nacionais sobre o número de eleitores indígenas alistados na Justiça Eleitoral, há sinais de que esse grupo vem crescendo justamente quando considerados outros fatores de participação política, como o número de candidaturas indígenas.

Assunto ainda pouco tratado no campo do Direito Eleitoral, mas já explorado em outros, como no Direito Constitucional e nos Direitos Humanos, o tema dos direitos políticos dos povos indígenas instiga ao menos uma análise mais detalhada e que combine a normativa internacional protetiva já existente com as disposições sobre os direitos indígenas no ordenamento jurídico brasileiro, tidos como ainda recentes em nível constitucional.

Assim, este breve ensaio tem como objetivo trazer um apanhado geral dos direitos políticos dos autóctones, partindo do disposto na Convenção 169 da OIT, para logo acrescentar as normas constantes nos sistemas onusiano e interamericano. Após, serão expostas as regras brasileiras tanto no âmbito constitucional quanto na legislação ordinária, trazendo algumas impressões vindas desde a aplicação dessas regras pela Justiça Eleitoral. Essa análise de regramento virá acompanhada de algumas decisões judiciais que demonstram como isso vem ocorrendo nos últimos anos proferidas tanto na esfera interamericana quanto pelo Poder Judiciário brasileiro.

Como esclarecimento necessário, nesse trabalho entender-se-á como índio o indivíduo que se identifique como tal segundo a consciência de seu vínculo histórico com a sociedade pré-colombiana, bem como aquele que a própria comunidade indígena que ele afirma pertencer ou reconhece como tal. Essa definição engloba dois critérios utilizados pela FUNAI para a tarefa ${ }^{2}$, o do autorreconhecimento e o do heterorreconhecimento, cons-

\footnotetext{
${ }^{1}$ Cf. < https:/ indigenas.ibge.gov.br/graficos-e-tabelas-2.html> Acesso em 12 jul. 2019.

2 Cf. < http://www.funai.gov.br/index.php/todos-ouvidoria/23-perguntas-frequentes/ 97-pergunta-3> Acesso em 10 jul. 2019.
} 
tantes no art. $1^{3}$ da Convenção 169 da Organização Internacional do Trabalho (OIT) ${ }^{4}$, bem como no art. 3, I do Estatuto do Índio (Lei nº 6.001/73). Rechaça-se a definição do índio como silvícola, por se entender que é uma definição pejorativa e que alimenta o estereótipo do indígena como um selvagem, que vive na selva e que é inferior em um hipotético estágio evolucionário das culturas (do selvagem à civilizada europeia) ${ }^{5}$. Esta, aliás, foi uma observação feita pelo Min. Ayres de Britto, quando do julgamento do Caso Raposa Serra do Sol no Supremo Tribunal Federal (Pet. 3.388, julg. 19/03/2009). Ainda, os direitos políticos aqui tratados centrar-se-ão no direito de votar e ser votado, uma vez que são prerrogativas básicas de qualquer cidadão, embora, dentro do tema de participação política dos indígenas, haja um vasto leque de ações que possam ser incluídas, como o direito à consulta prévia, por exemplo.

\section{O direito à autodeterminação dos povos indígenas}

A autodeterminação dos povos indígenas é, nas palavras de André de Carvalho Ramos, constituída por um tripé, sem cujos elementos não se alcança a efetivação desse princípio: território, governo e jurisdição ${ }^{6}$. Nesse sentido, a autodeterminação não é exclusiva aos indígenas, mas de todos os povos como organização social, como forma de manter suas características e de reconhecer suas culturas ${ }^{7}$.

\footnotetext{
${ }^{3}$ 1. A presente convenção aplica-se: a) aos povos tribais em países independentes, cujas condições sociais, culturais e econômicas os distingam de outros setores da coletividade nacional, e que estejam regidos, total ou parcialmente, por seus próprios costumes ou tradições ou por legislação especial; b) aos povos em países independentes, considerados indígenas pelo fato de descenderem de populações que habitavam o país ou uma região geográfica pertencente ao país na época da conquista ou da colonização ou do estabelecimento das atuais fronteiras estatais e que, seja qual for sua situação jurídica, conservam todas as suas próprias instituições sociais, econômicas, culturais e políticas, ou parte delas. 2. A consciência de sua identidade indígena ou tribal deverá ser considerada como critério fundamental para determinar os grupos aos que se aplicam as disposições da presente Convenção.

${ }^{4}$ Aprovada em 1989 e promulgada integralmente no Brasil pelo Decreto Presidencial no $5.051 / 2004$.

${ }^{5}$ RAMOS, André de Carvalho. Curso de Direitos Humanos. 4. ed. São Paulo: Saraiva, 2017. p. 781.

${ }^{6}$ Ibidem. p. 288.

${ }^{7}$ SOUZA FILHO, Carlos Frederico Marés. Comentário aos artigos 231 e 232. In: CANOTILHO, J. J. Gomes; MENDES, Gilmar Ferreira; SARLET, Ingo Wolfgang; STRECK, 
Embora já existente desde o século XIX ${ }^{8}$, a autodeterminação dos povos vem sendo construída como princípio desde o sistema institucional da Organização das Nações Unidas, consolidando-se em um ambiente no qual os próprios Estados-nação optaram por se submeter a uma nova ordem mundial. Assim, a ONU elencou como um de seus propósitos a composição de "relações amistosas entre as nações, baseadas no respeito ao princípio de igualdade de direitos e de autodeterminação dos povos" (art. 1.2 da Carta da ONU), bem como trouxe tratamento normativo a esse princípio no Pacto Internacional de Direitos Civis e Políticos e de Direitos Econômicos, Sociais e Culturais. A partir disso, tal princípio, antes percebido como de ordem política e moral, passou a se destacar como uma regra jurídica9 .

Conforme o preâmbulo da Constituição Federal de 1988, o Brasil se constitui em uma sociedade fraterna, plural e sem preconceitos. No entanto, no que se refere aos indígenas, ainda há muito que ser feito. No máximo, o que se percebe é a adoção de um multiculturalismo ${ }^{10}$ ainda contido, que se ocupa da diversidade enquanto diferença cultural, dentro de um determinado espaço (local, regional, nacional ou internacional), ao mesmo tempo em que repudia ou deixa de lado diferenças econômicas e sociopolíticas ${ }^{11}$.

Para ser um Estado multicultural, não basta que sejam aceitas as diferenças culturais, como sugere o caso brasileiro. É preciso que se dê autossuficiência para esses grupos, considerando-se as diferenças econômicas e as políticas. Não é possível consolidar um verdadeiro multiculturalismo sem primeiro honrar a autonomia desses povos, e é aqui que se encaixa o

Lenio Luiz. (Coords.). Comentários à Constituição do Brasil. São Paulo: Saraiva/Almedina, 2013. p. 4661-4678.

${ }^{8}$ BARBOSA, Marco Antônio. Autodeterminação direito à diferença. São Paulo: Plêiade, 2001. p. 302.

${ }^{9}$ Ibidem. p. 317.

${ }^{10}$ Multiculturalismo é um "modelo de gestão" sobre uma sociedade onde a diversidade é aceita e é valorizada. "Pode ainda influir na diminuição das desigualdades ao contemplar a diferença como fator de igualdade”. MELO, José Wilson Rodrigues de. Multiculturalismo: tensões brasileiras do direito à diferença como expressão de igualdade e dignidade. Revista ESMAT, [S.1.], v.8, n. 11, p. 91-104, jul./dez. 2017.

11 VERDRUM, Ricardo. Povos indígenas no Brasil: o desafio da autonomia. In: VERDRUM, Ricardo (org.). Povos indígenas: Constituições e reformas políticas na América Latina. Brasília: Coronário. 2009. p. 93. 
princípio da autodeterminação dos povos. Não há o que se falar em direito à autodeterminação de minorias étnicas se for esquecido o respeito às formas de ser e de viver particulares dos grupos, pois ela é baseada numa configuração de diversidade sociocultural, tendo em vista que o Estado brasileiro assumiu um papel não de tutor, mas sim de colaborador dos povos indígenas a partir do reconhecimento de sua autonomia, no art. 231 do texto constitucional ${ }^{12}$.

Nesse ponto, também se deve mencionar que as disposições constitucionais de 1988 são anteriores à aprovação da Convenção 169 da OIT, ocorrida em 1989. E, em relação especificamente à autodeterminação indígena, consagrou-se esse princípio no artigo 231, caput, da Constituição de 1988: "são reconhecidos aos índios sua organização social, costumes, línguas, crenças e tradições".

A autodeterminação está associada ao reconhecimento do modo de viver e de suas instituições, ainda que não oficiais (contanto que elas sejam sabidamente tradicionais), e de que elas sejam levadas em consideração nas tomadas de decisão. O direito ao reconhecimento que têm os indígenas passa antes pela existência de instituições extraestatais e sua validação. A autodeterminação pressupõe autonomia e esta é uma manifestação de vontade, que enseja voz e participação, compondo a ideia de um Estado Democrático de Direito ${ }^{13}$.

Assim, o princípio deve ser entendido como autogestão, não como uma autonomia política no sentido de independência política, mas sim no sentido de participação política para que, através dela, os indígenas possam ser protagonistas do seu próprio desenvolvimento econômico, e que possam também defender a perpetuação de suas heranças culturais, das tradições e de seus etnosaberes ${ }^{14}$.

12 SANTOS, Rodrigo Mioto dos. Pluralismo, multiculturalismo e reconhecimento uma análise constitucional do direito dos povos indígenas ao reconhecimento. Revista da Faculdade de Direito UFPR, [S.I.], v. 43, n. 0, 2005.

${ }^{13}$ WEBER, Thadeu. Autonomia, dignidade da pessoa humana e respeito em Kant. In: UTZ, Konrad; et al (coor.). Sujeito e liberdade: investigações a partir do idealismo alemão. Porto Alegre: EdiPUCRS, 2012. p. 14-43.

${ }^{14}$ Etnosaberes são conhecimentos, métodos, técnicas, formas de classificação e organização das suas vidas com o mundo natural. Em outras palavras, são o know-how, as práticas, a expertise, produzidas, utilizadas e transmitidas pelos grupos indígenas, que constituem seu patrimônio imaterial, e não se confundem com os saberes científicos nossos (dos não índios), mas têm a mesma - ou, até mesmo, superior - credibilidade dentre os indígenas, 
Segundo Norbert Rouland, o direito à autodeterminação para os autóctones é um direito à coexistência pacífica no interior do Estado com o resto da população, aliado com o poder de decidir seu destino perante as autoridades estatais, com direta conexão com os direitos políticos ${ }^{15}$.

Dessa forma, não há como dissociar o direito à autodeterminação dos povos indígenas de seus direitos políticos. Dar voz e possibilitar canais de participação na esfera pública garante o direito à autodeterminação aos indígenas, que requer que essa voz seja ativa e tida em conta nas decisões tomadas pelo Estado.

\section{Convenção 169 da OIT}

Embora não tenha sido a primeira a ser dirigida aos povos indígenas, a Convenção 169 da OIT é pioneira no que se refere ao seu efeito vinculante e que segue vigente.

Em um primeiro momento, a Convenção pretendia proporcionar aos povos indígenas e tribais o gozo ao trabalho, porém, com as mesmas garantias trabalhistas destinadas aos povos não índios. Também era seu objetivo compelir as nações a atuarem na salvaguarda de direitos trabalhistas e previdenciários. No entanto, o documento foi além da temática trabalhista, conformando um texto preocupado com os direitos sociais dos indígenas, como a educação e saúde, dentre outras providências de caráter territorial, cultural e patrimonial.

pois são conhecimentos tradicionais e transgeracionais. A transmissão desses etnosaberes ocorre mediante oralidade, exclusivamente. E mais: são adquiridos empiricamente, depois de processos de experimentações visuais, auditivas ou de percepção. Por exemplo, os conhecimentos a respeito da flora, a sapiência que detêm acerca das plantas e das propriedades medicinais de cada uma delas, são etnosaberes e não podem ser desprezados pois muitos benefícios curativos atribuídos à algumas plantas, posteriormente se confirmam como sendo eficazes por estudos científicos. Outro exemplo sobre o que compreende etnosaberes são os estudos milenares da etnia dos Tupinambás, que já tinham elaborado há muito uma taxonomia de alguns animais da Amazônia brasileira, engendrando a etnobiologia indígena. (Cf. SILVA, Ana Paula da; FREIRE, José Ribamar Bessa. As palavras e a letra: etnosaberes Tupinambá nas fontes coloniais. Disponível em: <http:/ /www. snh2011.anpuh.org/resources/anais/14/1308326908_ARQUIVO_Artigo_Anpuh_Nacional_2011_Ana_Paula_em06abr11_alterado_Haverroth_em07abr11.pdf > Acesso em 12 jul. 2019).

${ }^{15}$ ROULAND, Norbert; PIERRÉ-CAPS, Stephane; POUMARÈDE, Jacques. Droit des minorités et des peuples autochtones. Paris: Presses Universitaires de France, 1996. 
O texto da Convenção também traz linhas sobre ações governamentais com base na livre determinação, ao direito de usufruto de terras, direito à preservação da identidade cultural do povo, além do direito a usar e administrar os recursos naturais, resguardando o direito à indenização plena por perdas e danos. Esse contexto aproximou muitas áreas do Direito aos Direitos Humanos, o que colabora na ideia de indivisibilidade desses direitos ${ }^{16}$ e ajuda a gerar uma consciência sobre a necessidade de tutela dos direitos desses povos, que, como se sabe, não gozam materialmente dos mesmos direitos que os demais da população ${ }^{17}$.

Os principais propósitos trazidos pela Convenção foram: (i) definição sobre os destinatários da Convenção; (ii) estabelece um sentido para a interpretação do termo 'povos', que não deve ser admitido como tendo o mesmo empregado em ‘povo’ para o Direito Internacional; (iii) autoidentificação, que se refere à noção de reconhecimento de sua identidade indígena como um critério subjetivo, bem como a identificação heterônoma, que vem por terceiros; (iv) princípio da não discriminação, conferindo pleno gozo de direitos humanos e direitos fundamentais sem discriminação; (v) autonomia, dentro do marco da autodeterminação; (vi) reconhecimento dos direitos reais de usufruto, tendo como base a importância da relação que esses povos têm com suas terras e territórios; (vii) direito de preservação da cultura e valores, através da tolerância e através de políticas educacionais que visem a essa preservação; e (viii) direito de serem previamente consultados sobre decisões que os afetem direta ou indiretamente.

Cabe mencionar que a Convenção surge em um período histórico rico em mudanças ou reformas nas Constituições em distintos países latino-americanos ${ }^{18}$, como foi o caso brasileiro. Com o processo redemo-

\footnotetext{
${ }^{16}$ André de Carvalho Ramos entende que a indivisibilidade possui duas facetas, sendo a primeira a que implica reconhecer que o direito tutelado apresenta uma unidade indissolúvel em si; e a segunda, mais difundida, é a de que não é possível proteger apenas alguns dos direitos humanos reconhecidos. É a partir dessa perspectiva que se exige dos Estados o investimento tanto nos direitos de primeira, como também de segunda e terceira dimensões (cf. CARVALHO RAMOS, André de. Teoria geral dos direitos humanos na ordem internacional. 6. ed., São Paulo: Saraiva, 2016).

${ }^{17}$ BALDI, César Augusto; RIBEIRO, Lilian Márcia de Castro. A proposta de revogação da convenção 169 da OIT pelo Brasil e o princípio da vedação do retrocesso social. Fragmentos de Cultura. Goiânia, v. 25, n. 2, p. 241-252, abr./jun. 2015.

${ }^{18}$ BRAUN, Helenice da Aparecida Dambrós. Efetividade dos direitos trabalhistas dos indígenas e seus instrumentos jurídicos: uma análise das demandas trabalhistas das Resenha Eleitoral (Florianópolis), v. 23, n. 2, p. 11-34, 2019
} 
cratizador do Brasil, e, ao ratificar instrumentos internacionais normativos protetivos ao indígena, o país fez uma clara opção pela garantia de direitos indígenas ${ }^{19}$.

\section{Os direitos políticos na normativa universal e interamericano de direitos humanos}

Uma das consequências diretas das guerras mundiais foi a internacionalização dos direitos humanos, uma vez que, até então, o Direito Internacional continha apenas algumas normas esparsas que se referiam a certos direitos essenciais. Um marco nesse processo foi a criação da Organização das Nações Unidas (ONU), em 1945. Nesse período, ficou evidente que os direitos políticos seriam muito importantes para o resgate e a reconstrução dos regimes democráticos, a partir da reestruturação dos partidos políticos, da realização de eleições livres, diretas, com voto universal ${ }^{20}$. Isso, para todos e sempre pautados pelo princípio da autodeterminação dos povos.

A partir de então, foram aprovados diversos documentos internacionais, no sentido de formar um consenso entre os países sobre o conteúdo desses direitos, fazendo-os universais, ou seja, aplicáveis a todos os Estados que aderissem ao seu texto. No final da década de 40, dois documentos de suma importância foram aprovados: a Declaração Universal dos Direitos Humanos $^{21}$, que corresponde às Nações Unidas, e a Declaração Americana dos Direitos e Deveres do Homem ${ }^{22}$, conectada com a Organização dos Estados Americanos (OEA), criada em $1948^{23}$.

comunidades indígenas em Chapecó. Florianópolis, 2016. 356 f. Tese (Doutorado em Direito) - Centro de Ciências Jurídicas, pós-graduação em Direito, Universidade Federal de Santa Catarina. p. 65.

${ }^{19}$ ARAÚJO, Sílvia Dettmer; MORAES, Júlia Thais de Assis. Breve análise entre a Constituição Federal e a institucionalização dos direitos fundamentais no contexto indígena. Revista Aporia Jurídica, [S.1], v. 1, n. 8, p. 228- 240, jul-dez, 2017.

${ }^{20}$ Nesse período, a questão do voto feminino já vinha sendo solucionada em muitos países, como Reino Unido (1918), EUA (1920), Uruguai (1927), Equador (1929) e Brasil (1932). Inclusive, durante este período entre guerras, as mulheres adquiriram o direito ao voto em mais de 28 países (Cf.<http://www.bbc.com/mundo/noticias/2013/10/131018_100_ mujeres_bastiones_feminismo_vs $>$ Acesso em 14 jun. 2019).

${ }^{21}$ O Brasil assinou o documento no momento de sua aprovação, em 1948.

${ }^{22} \mathrm{O}$ Brasil assinou o documento no momento de sua aprovação, também em 1948.

${ }^{23}$ Nesse ponto, uma advertência deve ser feita. Há uma falsa ideia de que a Declaração Universal dos Direitos Humanos, referente ao sistema onusiano de proteção, foi aprova- 
Na Declaração Universal de Direitos Humanos (DUDH) ${ }^{24}$, o princípio da liberdade possui tanto a dimensão política quanto a individual, sendo, portanto, complementares e interdependentes ${ }^{25}$. Não há uma sem a outra. Nesse sentido, a DUDH dispõe em seu art. XXI que todo homem tem o direito de tomar parte no governo de seu país, diretamente ou por meio de representantes. $\mathrm{O}$ acesso aos serviços públicos também é garantido a todos. Já no que tange à soberania popular, a DUDH estabelece que a vontade do povo seja a base da autoridade do governo, expressada em eleições periódicas e legítimas por sufrágio universal, voto secreto ou algum processo equivalente que garanta a liberdade de voto.

Ainda no sistema de proteção aos Direitos Humanos da ONU, em 1966 foi aprovado o Pacto Internacional dos Direitos Civis e Políticos que, juntamente com o Pacto dos Direitos Sociais, Econômicos e Culturais $^{26}$, visava tornar juridicamente vinculantes os direitos já constantes na DUDH, detalhando-os e trazendo mecanismos de monitoramento sobre o seu cumprimento pelos Estados-parte. Constam no art. 25 os direitos de participação política, que asseguram a todos, sem qualquer discriminação, o direito de participar dos assuntos públicos, diretamente ou por meio de representantes livremente escolhidos. Garante também o direito de votar e ser eleito em eleições periódicas, autênticas, realizadas por sufrágio uni-

da antes da Declaração Americana dos Direitos e Deveres do Homem, que responde ao sistema interamericano. Na verdade, é justamente o contrário: a Declaração Americana foi aprovada durante a $9^{\mathrm{a}}$ Conferência Interamericana, em Bogotá, entre os dias 30 de março e 2 de maio de 1948, enquanto a Declaração Universal foi aprovada sob a forma de Resolução da Assembleia Geral da ONU, em 10 de dezembro de 1948, em Paris.

${ }^{24} \mathrm{~A}$ Carta da ONU não listou um rol de direitos essenciais, o que levou à aprovação da DUDH. No entanto, cabe destacar aqui a natureza declaratória da DUDH, o que não faz dela um tratado internacional. Isso gera um debate doutrinário sobre a sua força vinculante, dividindo-se em 3 (três) correntes: (i) teria força vinculante por ser uma interpretação autêntica do termo "direitos humanos" constante na Carta da ONU; (ii) teria força vinculante por representar o costume internacional sobre a matéria; (iii) seria somente soft law, ou seja, um conjunto de normas ainda não vinculantes, mas que buscam direcionar as ações dos Estados para, então, ter força vinculante (Cf. RAMOS, André de Carvalho. Curso de direitos humanos. 4. ed. São Paulo: Saraiva, 2017. p. 50).

${ }^{25}$ COMPARATO, Fábio Konder. A afirmação histórica dos Direitos Humanos. 10. ed. São Paulo: Saraiva, 2016. p. 242.

${ }^{26}$ O Pacto Civil foi ratificado pelo Brasil por meio do Decreto $\mathrm{n}^{\mathrm{9}} 592$, de 6 de julho de 1992, e o Pacto Econômico foi pelo Decreto n 591, do mesmo dia. Com relação a este último, não há ainda a ratificação do seu Protocolo Adicional, que submete o Brasil ao sistema de monitoramento por peticionamento.

Resenha Eleitoral (Florianópolis), v. 23, n. 2, p. 11-34, 2019 
versal e igualitário, por voto secreto e que assegurem a manifestação da vontade dos eleitores. Ao final do dispositivo, há a garantia do acesso, em condições gerais de igualdade, às funções públicas de seu respectivo país.

Ainda a esse respeito, o Comitê de Direitos Humanos das Nações Unidas se pronunciou sobre o art. 25 do Pacto Civil, trazendo algumas considerações de sua aplicação na Observação Geral nº 25. Nesse documento, afirma-se que os Estados devem prezar pelo direito ao voto, sempre agindo positivamente para garantir esse direito a todos, combatendo fatores que fazem com que alguém não consiga votar. A mesma postura os Estados devem ter no que se refere ao direito de serem votados, tomando como base o direito à autodeterminação e à participação nos assuntos públicos ${ }^{27}$.

Já no que tange ao sistema interamericano de direitos humanos, a Carta da OEA trouxe em seu texto a cláusula democrática (art. 9), que prevê a possibilidade de suspensão de algum Estado membro devido à derrubada à força de um governo democraticamente eleito ${ }^{28}$. Complementando a Carta, a Declaração Americana dos Direitos e Deveres do Homem dispõe ${ }^{29}$, em seu art. XX, que toda pessoa legalmente capacitada tem o direito de tomar parte no governo do seu país, seja direta ou indiretamente por meio de representantes, bem como de participar das eleições, através do voto secreto, de forma genuína, periódica e livre. Atestam-se, aqui, a soberania popular e os moldes de democracia que se consideram imprescindíveis para os direitos humanos.

Essa proteção aos direitos políticos repete-se na Convenção Americana sobre os Direitos Humanos, conhecida também como Pacto de San

${ }^{27}$ NACIONES UNIDAS. Comentarios generales adoptados por el Comité de los Derechos Humanos, Artículo 25 - La participación en los asuntos públicos y el derecho de voto, 57ํ período de sesiones, U.N. Doc. HRI/GEN/1/Rev.7 at 194 (1996). Disponível em:<http://hrlibrary.umn.edu/hrcommittee/Sgencom25.html> Acesso em 11 jul. 2019.

${ }^{28}$ Assim consta no art. 9: "Um membro da Organização, cujo governo democraticamente constituído seja deposto pela força, poderá ser suspenso do exercício do direito de participação nas sessões da Assembléia Geral, da Reunião de Consulta, dos Conselhos da Organização e das Conferências Especializadas, bem como das comissões, grupos de trabalho e demais órgãos que tenham sido criados." (...).

${ }^{29}$ A Declaração Americana é considerada uma interpretação autêntica dos dispositivos genéricos de proteção de direitos humanos da Carta da OEA, segundo a Corte Interamericana de Direitos Humanos, no Parecer Consultivo sobre a interpretação da Declaração Americana dos Direitos e Deveres do Homem, art. 64 da Convenção, 1989, \44. 
José da Costa Rica $(1969)^{30}$, no seu art. 23, garantindo a todos os cidadãos o direito de participar na direção dos assuntos públicos, diretamente ou por meio de representantes livremente eleitos, de votar e ser eleitos em eleições periódicas autênticas, realizadas por sufrágio universal e igual, e por voto secreto que garanta a livre expressão da vontade dos eleitores, e de ter acesso, em condições gerais de igualdade, às funções públicas de seu país. Ainda, o Pacto de San José estabelece que uma lei possa regular o exercício dos direitos políticos do art. 23, pautando-se exclusivamente por motivos de idade, nacionalidade, residência, idioma, instrução, capacidade civil ou mental, ou condenação, por juiz competente, em processo penal, algo que vem causando muito conflito entre o entendimento da Comissão e da Corte Interamericana de Direitos Humanos e os ordenamentos jurídicos dos Estados-parte da Convenção ${ }^{31}$.

Uma tutela mais detalhada dos direitos políticos veio com a aprovação da Carta Democrática, em 11 de setembro de 2001. Ainda que não tenha natureza de tratado, uma vez que foi aprovada como resolução da Assembleia Geral da OEA sendo, portanto, uma soft law e não vinculante, constitui-se em um importante vetor de interpretação para a promoção da democracia nos continentes americanos ${ }^{32}$. Em seus 28 artigos, constam 6

${ }^{30}$ Promulgado pelo Brasil através do Decreto Presidencial no 678, de 6 de novembro de 1992.

31 Tanto a Comissão Interamericana de Direitos Humanos quanto a Corte já tiveram oportunidade de se manifestar sobre essas vedações no caso Yatama vs. Nicarágua (decisão de 23 de junho de 2005), López Mendoza vs. Venezuela (decisão de 01 de setembro de 2011), Gustavo Petro Urrego vs. Colômbia (com medida cautelar imposta pela Comissão Interamericana de Direitos Humanos desde 2014), dentre outros. Nesses casos, o que se debate é o direito de ser eleito - e permanecer eleito -, diante de decisões de órgãos outros que não sejam uma condenação, por juiz competente, em processo penal. Para uma análise mais detalhada sobre esses casos, vd. por todos: AMAYA, Jorge Alejandro; LOIANNO, Adelina. Derechos Políticos y medidas cautelares de la CIDH: reflexiones e interrogantes del caso 'Gustavo Petro'. Revista Iberoamericana de Derecho Procesal Constitucional n⿳ 21, p. 295-321, ene./jun. 2014; e AMAYA, Jorge Alejandro. Tensiones entre decisiones de los órganos del Sistema Interamericano de Derechos Humanos y el derecho interno de los Estados en materia de derechos políticos. Lex. no 18, año XIV, p. 19-33, 2016.

${ }^{32} \mathrm{O}$ entendimento de Asdrúbal Aguiar traz exatamente a forma como a democracia deve ser entendida, conjugando seus elementos essenciais com a democracia de exercício, que trata sobre a efetividade de seu exercício, além de elevá-la como um direito humano das pessoas e dos povos (Cf. AGUIAR, Asdrúbal. La democracia en la jurisprudencia de la Corte Interamericana de Derechos Humanos: 1987-2012. In: PÉREZ CORTI, José María (dir.). Memoria del Io Congreso Argentino de Derecho Electoral. Buenos Aires: Infojus, 2012. p. 38-39).

Resenha Eleitoral (Florianópolis), v. 23, n. 2, p. 11-34, 2019 
partes: (i) democracia e sistema interamericano; (ii) democracia e os direitos; (iii) democracia, desenvolvimento integral e combate à pobreza; (iv) fortalecimento e preservação da institucionalidade democrática; (v) democracia e as missões de observação eleitoral ${ }^{33}$; (vi) promoção da cultura democrática ${ }^{34}$.

No que se refere ao objeto desse trabalho, as disposições dos arts. 3, 4 e 6 abordam justamente o respeito aos direitos humanos e às liberdades fundamentais; a realização de eleições periódicas; livres e justas; o sufrágio universal e secreto como expressão da soberania do povo; o pluralismo de partidos políticos e a separação de poderes $^{35}$; a transparência, probidade e responsabilidade na gestão pública ${ }^{36}$; bem como o art. 6 ressaltando a importância da participação popular, como direito e responsabilidade para o exercício da democracia, devendo ser sempre ampliada para o fortalecimento desse sistema ${ }^{37}$.

${ }^{33}$ Sobre o tema, cf. SANTANO, Ana Claudia. Observação eleitoral internacional: por que o Brasil não adere a esta ideia? Sugestões para uma maior integração democrática regional. In: MORAES, Filomeno; SALGADO, Eneida Desiree; AIETA, Vânia Siciliano. (Org.). Justiça eleitoral, controle das eleições e soberania popular. Curitiba: Íthala, 2016, v. 1, p. 11-44. ${ }^{34}$ Sobre o tema, cf. PRIOTTTI, Anahí; TRUCCO, Marcelo. La cláusula democrática en los procesos de integración latinoamericana. RecorDip - Revista electrónica cordobesa de derecho internacional público. v. 2, n. 2, 2012. Disponível em: <https://revistas.unc.edu. ar/index.php/recordip/article/view/3027> Acesso em 11 jul. 2019.

${ }^{35}$ Art. 3: "São elementos essenciais da democracia representativa, entre outros, o respeito aos direitos humanos e às liberdades fundamentais, o acesso ao poder e seu exercício com sujeição ao Estado de Direito, a celebração de eleições periódicas, livres, justas e baseadas no sufrágio universal e secreto como expressão da soberania do povo, o regime pluralista de partidos e organizações políticas, e a separação e independência dos poderes públicos".

${ }^{36}$ Art. 4: "São componentes fundamentais do exercício da democracia a transparência das atividades governamentais, a probidade, a responsabilidade dos governos na gestão pública, o respeito dos direitos sociais e a liberdade de expressão e de imprensa. A subordinação constitucional de todas as instituições do Estado à autoridade civil legalmente constituída e o respeito ao Estado de Direito por todas as instituições e setores da sociedade são igualmente fundamentais para a democracia".

${ }^{37}$ Art. 6: "A participação dos cidadãos nas decisões relativas a seu próprio desenvolvimento é um direito e uma responsabilidade. É também uma condição necessária para o exercício pleno e efetivo da democracia. Promover e fomentar diversas formas de participação fortalece a democracia". 


\section{A jurisprudência interamericana sobre os direitos políticos dos indígenas}

Até o momento, há apenas um caso julgado pela Corte Interamericana de Direitos Humanos envolvendo direitos políticos de indígenas ${ }^{38}$. O caso Yatama vs. Nicarágua tem como início a adoção da Lei Eleitoral $n^{\circ}$ 331 de janeiro de 2000, que não contemplou a figura das associações de subscrição popular para que este povo indígena participasse das eleições, permitindo-se somente a participação nos processos eleitorais por meio da figura jurídica dos partidos políticos.

Em 8 de março de 2000, membros da organização indígena Yapti Tasba Masraka Nanih Asla Takanka (YATAMA) tentaram obter uma autorização para serem reconhecidos como um partido político regional. Contudo, apesar dos diversos recursos apresentados, a solicitação foi negada. Isso impediu a participação do Yatama nas eleições daquele ano ${ }^{39}$.

A Corte Interamericana de Direitos Humanos (em diante, CIDH) amparando-se no art. 23, inciso 2 do Pacto de San José, considerou que, efetivamente, a previsão e aplicação de requisitos para exercer os direitos políticos não constituem, per se, uma restrição indevida a tais direitos, que não são absolutos e que podem ser objeto de limitação. Contudo, a regulação em torno das "condições habilitantes" e outras "condicionantes e formalidades" permitidas pelo art. 23, inciso 2 da Convenção Americana, deve observar os princípios de legalidade, necessidade e proporcionalidade em uma sociedade democrática. Assim, a regulação não pode, segundo a CIDH, ser discriminatória, mas sim deve se basear em critérios razoáveis, atender a um propósito útil e oportuno que a torne necessária para satisfazer um interesse público imperativo, bem como ser proporcional a esse objetivo $^{40}$.

Por outro lado, dentro da noção de democracia trazida pelo Pacto de San José, também colacionados na Carta da OEA, o modelo representa-

\footnotetext{
${ }^{38}$ No entanto, cabe mencionar que há vasta jurisprudência sobre direitos dos povos indígenas no que se refere a direitos reais, desaparecimentos forçados e massacres contra esses grupos. Nesse sentido, cf. MAZZUOLI, Valério de Oliveira. Direitos humanos na jurisprudência internacional. Sentenças, opiniões consultivas, decisões e relatórios internacionais. São Paulo: Método, 2019.

${ }^{39}$ Cf. ficha técnica do caso em: <http://www.corteidh.or.cr/cf/Jurisprudencia2/ficha_ tecnica.cfm?nId_Ficha=268\&lang=es $>$ Acesso em 12 jul. 2019.

40 Tradução livre e paráfrase do parágrafo 206 da sentença.
}

Resenha Eleitoral (Florianópolis), v. 23, n. 2, p. 11-34, 2019 
tivo cede espaço para a democracia comunitária, como declarou o juiz García Sayán em seu voto. Há, dessa forma, o estabelecimento dos estandartes internacionais sobre a democracia e o seu exercício efetivo. A partir disso, a Carta Democrática Interamericana dispõe que a participação da cidadania nas decisões relativas ao seu próprio desenvolvimento é um direito e uma responsabilidade, que reforça e aprofunda a democracia representativa. Logo, a CIDH reconhece o direito à participação política das comunidades indígenas, por terem formas de organização tradicionais e próprias. Assim, a sentença sustenta que não existe disposição na Convenção Americana que permita afirmar que os cidadãos somente podem exercer o direito a se postular como candidatos a um cargo eletivo através de um partido político, e por isso mesmo que a participação nos assuntos públicos de organizações diversas dos partidos é essencial para garantir a expressão política legítima e necessária quando se trata de grupos de cidadãos que, de outra forma, poderiam ficar excluídos dessa participação ${ }^{41}$.

Ao final, Nicarágua foi condenada, dentre outras providências, a reformar a regulação dos requisitos dispostos na Lei Eleitoral n 331 de 2000, que foram declarados violadores da Convenção, bem como a adotar, em um prazo razoável, medidas necessárias para que os integrantes das comunidades indígenas e étnicas possam participar nos processos eleitorais de forma efetiva, tomando em conta as suas tradições, usos e costumes, no marco de uma sociedade democrática. Os requisitos que se estabeleçam devem permitir e fomentar que os membros dessas comunidades contem com uma representação adequada que lhes permita intervir nos processos de decisão sobre as questões nacionais que envolvam a sociedade em seu conjunto, bem como os assuntos particulares que se conectem com tais comunidades. Dessa forma, os requisitos a serem adotados não devem se constituir em um bloqueio de sua participação política ${ }^{42}$.

Nesse sentido, a CIDH aprofunda a noção de democracia para um modelo inclusivo, multicultural e comunitário ${ }^{43}$. A situação era, efetivamen-

${ }^{41}$ Tradução livre e paráfrase dos parágrafos 215 e 217 da sentença.

${ }^{42}$ Tradução livre e paráfrase do parágrafo 259 da sentença. Com base na resolução de supervisão de cumprimento de sentença de 30 de junho de 2011, a decisão não foi inteiramente cumprida pelo Estado da Nicarágua, havendo novamente a interpelação da CIDH para que as sanções sejam cumpridas em sua integridade.

${ }^{43}$ AGUIAR, Asdrúbal. La democracia en la jurisprudencia de la Corte Interamericana de Derechos Humanos: 1987-2012. In: PÉREZ CORTI, José María (dir.). Memoria del Io Congreso Argentino de Derecho Electoral. Buenos Aires: Infojus, 2012. p. 60-61. 
te, desproporcional, uma vez que o grupo Yatama tentou ver-se registrado como um partido, sem sucesso. Foi, portanto, bloqueado, mesmo na tentativa de se institucionalizar e ser mais uma agremiação no mercado político nicaraguense. Poder-se-ia, inclusive, aplicar aqui um pensamento assimilacionista, já que a normativa eleitoral da Nicarágua não tratou de observar o direito à diferença e às tradições desse grupo de indígenas, mas sim impôs a homogeneização dos movimentos políticos para o formato de partidos, a fim de possibilitar a sua participação nas eleições daquele país.

\section{Os direitos políticos dos indígenas no Brasil}

Dentro do marco constitucional, os indígenas possuem o direito de sufrágio dentro da regra geral do art. 14, \1‥ Contudo, há certas peculiaridades que devem ser consideradas e que exigem uma leitura conjugada com outras normas ainda vigentes, como o Estatuto do Índio, o Código Eleitoral (Lei 4.737/1965, com alterações posteriores) e as resoluções aprovadas pelo Tribunal Superior Eleitoral.

Ainda vigente, o Estatuto do Índio (Lei no 6.001/1973) se constitui em uma norma de duvidosa recepção pelo texto constitucional. Essa lei possui o claro objetivo de colocar os indígenas em um processo de assimilação, ou seja, estabelecer que a sua condição de índio seja transitória e que, com o tempo, ele deveria estar "integrado". Isso contraria terminantemente o espírito da Constituição Federal de 1988 e da Convenção no 169 da OIT, como já visto ${ }^{44}$.

Nesse diploma normativo, os índios são considerados dentro de três categorias de civilização: (i) isolados, que vivem em grupos desconhecidos e têm pouco ou nenhum contato com a sociedade; (ii) em via de integração, ou seja, aqueles que estão em permanente contato com a sociedade, embora preservem seus costumes e aceitem algumas práticas e modos de existência diversos dos seus; (iii) integrados, reconhecidos no pleno exercí-

\footnotetext{
${ }^{44}$ Sobre o tema, cf. ANJOS FILHO, Robério Nunes dos. Breve balanço dos direitos das comunidades indígenas: alguns avanços e obstáculos desde a Constituição de 1988. Revista Brasileira de Estudos Constitucionais - RBEC, Belo Horizonte, ano 2, n. 8, out./dez. 2008. Disponível em: <http://www.bidforum.com.br/PDI0006.aspx?pdiCn$\mathrm{td}=56008>$ Acesso em 12 jul. 2019; RODRIGUES, Ricardo José Pereira. Democracia e Participação Política dos Povos Indígenas: a questão da representação especial. Interesse Público - IP, Belo Horizonte, ano 16, n. 88, nov./dez. 2014. Disponível em: < http:/ /www. bidforum.com.br/PDI0006.aspx?pdiCntd=230453> Acesso em 12 jul. 2019.
} 
cio de direitos civis. A mesma norma estabelece que índios e comunidades indígenas ainda não integrados fiquem sujeitos ao regime tutelar da União, existindo a possibilidade de que qualquer indígena pode requerer sua liberação do regime tutelar e, assim, adquirir a plenitude da capacidade civil ${ }^{45}$.

Dentro desse texto legal, há dispositivos que colidem frontalmente com a Constituição Federal de 1988. Segundo o art. 2², cumpre à União, aos Estados e aos Municípios, bem como aos órgãos das respectivas administrações indiretas, nos limites de sua competência, para a proteção das comunidades indígenas e a preservação dos seus direitos. Dentre esses direitos, deve-se, nos termos do inciso $\mathrm{X}$, garantir aos índios o pleno exercício dos direitos civis e políticos que em face da legislação lhes couberem. $\mathrm{O}$ conflito vem com o disposto no art. 5ª que estabelece que se aplicam aos índios ou silvícolas (com a utilização de uma nomenclatura já superada) as normas dos artigos 145 e 146, da Constituição Federal (da então vigente, a de 1969), relativas à nacionalidade e à cidadania, e que o exercício dos direitos civis e políticos pelo índio depende da verificação das condições especiais estabelecidas no Estatuto e na legislação pertinente. É nesse ponto que, no art. $7^{\circ}$, fixa-se que os índios e as comunidades indígenas ainda não integrados à comunhão nacional ficam sujeitos ao regime tutelar estabelecido nesta Lei.

Cabe mencionar que se entende, nesse trabalho, que tais dispositivos não são mais aplicáveis devido à hierarquia das normas, tanto com relação à não recepção constitucional dessas regras, como também com o Pacto Civil da ONU e a Convenção Interamericana de Direitos Humanos, ambos diplomas tidos como supralegais no ordenamento jurídico brasileiro.

Por outro lado, o Código Eleitoral, também aprovado muito antes da promulgação da Constituição Federal de 1988, contém diversas regras, também de duvidosa recepção constitucional, sobre os direitos políticos dos indígenas. Os índios, assim como os demais cidadãos brasileiros, devem votar se tiverem mais de 18 anos e forem alfabetizados em língua portuguesa. Será somente nessa condição (alfabetizado em língua portuguesa)

\footnotetext{
${ }^{45}$ Cf. ARTILHEIRO, Marcelo Feliz. Dos direitos eleitorais dos indígenas. Resenha eleitoral - Revista técnica. n. 7, jan./jun. 2015. Disponível em: <http://www.tre-sc.jus.br/ site/resenha-eleitoral/revista-tecnica/edicoes/n-7-janjun-2015/integra/indexf5c5.html?no_cache $=1 \&$ tx_news_pi $1 \% 5 \mathrm{Bnews} \% 5 \mathrm{D}=9372 \&$ tx_news_pi $1 \% 5 \mathrm{Bmonth} \% 5 \mathrm{D}=$ June $\&$ tx_news_pi1 $\% 5$ Byear $\% 5 \mathrm{D}=2015 \& \mathrm{cHash}=\mathrm{c} 367 \mathrm{f} 6 \mathrm{c} 8796 \mathrm{ea} 0 \mathrm{a} 1 \mathrm{e} 0035005 \mathrm{e} 2 \mathrm{c} 4 \mathrm{de} 7 \mathrm{c}>$ Acesso em 12 jul. 2019.
} 
que o índio poderá se alistar para votar, considerando a vedação constante no art. 5ํํำ do Código Eleitoral para aqueles que não saibam exprimir-se na língua nacional. No entanto, caso os índios que vivem nas aldeias optem por não votar, essa decisão individual prevalece sobre a obrigatoriedade da lei brasileira ${ }^{46}$.

Nesse aspecto, diversos problemas jurídicos surgem e que vão desde antinomias com a ordem constitucional em vigor (art. 231), bem como as próprias resoluções do $\mathrm{TSE}^{47}$ e posteriores decisões que estabeleceram a não recepção constitucional dessa proibição via resolução ${ }^{48}$. Esse entendimento prossegue sendo aplicado pela Corte ${ }^{49}$.

${ }^{46}$ Cf. < http://www.tse.jus.br/imprensa/noticias-tse/2018/Abril/facilitar-o-voto-de-povos-indigenas-e-preocupacao-da-justica-eleitoral> Acesso em 10 jul. 2019.

${ }^{47}$ Resolução n⿳ 7.919, de 9 de setembro de 1966. "Os índios são alistáveis nas condições exigidas pelos artigos. 131 e 132 da Constituição Federal”. Referência à Constituição de 1946: Resolução 20.806, de 15 de maio de 2000: "Alistamento eleitoral. Exigências. São aplicáveis aos indígenas integrados, reconhecidos no pleno exercício dos direitos civis, nos termos da legislação especial (Estatuto do Índio), as exigências impostas para o alistamento eleitoral, inclusive de comprovação de quitação do serviço militar ou de cumprimento de prestação alternativa.” (Cf. FERREIRA, Lara Marina. Estudo preliminar, Eixo temático VII: participação feminina, jovens, negros, indígenas, pessoas com deficiência e presos. Diálogos para a construção da sistematização das normas eleitorais. Brasília: TSE, 2019. p. 9-10. Disponível em: < http://www.tse.jus.br/legislacao/sne/arquivos/gt-vii-eixo-transversal-estudo-preliminar> Acesso em 12 jul. 2019).

48 “'[... Recepção. Constituição Federal. Artigo 5º, inciso II, do Código Eleitoral. - Consoante o $\int 2^{\circ}$ do artigo 14 da CF, a não alistabilidade como eleitores somente é imputada aos estrangeiros, e durante o período do serviço militar obrigatório, aos conscritos, observada, naturalmente, a vedação que se impõe em face da incapacidade absoluta nos termos da lei civil. - Sendo o voto obrigatório para os brasileiros maiores de 18 anos, ressalvada a facultatividade de que cuida o inciso II do $\int 1^{\circ}$ do artigo 14 da CF, não há como entender recepcionado preceito de lei, mesmo de índole complementar à Carta Magna, que imponha restrição ao que a norma superior hierárquica não estabelece. - Vedado impor qualquer empecilho ao alistamento eleitoral que não esteja previsto na Lei Maior, por caracterizar restrição indevida a direito político, há que afirmar a inexigibilidade de fluência da língua pátria para que o indígena ainda sob tutela e o brasileiro possam alistar-se eleitores. - Declarada a não recepção do art. 5ㅜ, inciso II, do Código Eleitoral pela Constituição Federal de 1988.” (Res. no 23274, de 1.6.2010, rel. Min. Fernando Gonçalves)

49 "Processo administrativo. Solicitação. Alteração. Normas de serviço. Exigência. Apresentação. Comprovante. Quitação militar. Indígenas 'integrados’. Garantia. Alistamento eleitoral. Desinfluência. Categorização. Atendimento. Preceitos legais. Apresentação. Documentação comprobatória. 1. Os indígenas têm assegurado o direito de se alistar como eleitores e de votar, independentemente de categorização prevista em legislação especial infraconstitucional, a partir dos dezesseis anos, desde que atendidos os preceitos legais re- 
Para o alistamento eleitoral dos indígenas, o índio deve seguir o mesmo procedimento que qualquer cidadão, respeitando certas particularidades. $\mathrm{O}$ indígena que não tiver os documentos oficiais exigidos deve apresentar como documento válido o registro administrativo correspondente expedido pela Fundação Nacional do Índio (Funai). No entanto, há detalhes trazidos no Código Eleitoral que seguem dificultando o alistamento dos indígenas, como é o disposto no art. 42, referente ao domicílio eleito$\mathrm{ral}^{50}$. Ocorre que não há regulamentação sobre a forma de determinação do domicílio eleitoral do indígena, gerando um vácuo que pode afetar esse direito que nem mesmo o Estatuto do Índio sana, em seus arts. $22^{51}$ e $23^{52}$.

Outro ponto é a identificação eleitoral do indígena. $\mathrm{O}$ art. 44 do Código Eleitoral estabelece a exata identificação do indivíduo para requerer o alistamento eleitoral. Porém, há a ausência de regulamentação específica sobre a forma de identificação eleitoral dos indígenas, especialmente dos indígenas não integrados. Existem, na verdade, insuficientes regras nos arts.

gulamentadores da matéria, conforme orientação firmada por esta corte superior. 2. Todo cidadão do sexo masculino, maior de dezoito anos, que comparece a unidade eleitoral - cartório, posto ou central de atendimento - com a finalidade de se alistar eleitor, deve apresentar, entre outros documentos, comprovante de quitação das obrigações militares, nos exatos termos do art. 44, II, do Código Eleitoral. 3. Tendo em conta a desinfluência da classificação conferida ao indígena para esta justiça especializada e a garantia constitucional relativamente a sua organização social, costumes, línguas, crenças e tradições (Constituição, art. 231), será solicitado, na hipótese de requerer alistamento eleitoral, documento hábil obtido na unidade do serviço militar do qual se infira sua regularidade com as obrigações correspondentes, seja pela prestação, dispensa, isenção ou quaisquer outros motivos admitidos pela legislação de regência da matéria, em conjunto ou não com o do órgão competente de assistência que comprove a condição de indígena, ambos estranhos à órbita de atuação da justiça eleitoral”. (Ac. de 10.2.2015 no PA nº 191930, rel. Min. João Otávio de Noronha)

${ }^{50}$ Art. 42. O alistamento se faz mediante a qualificação e inscrição do eleitor.

Parágrafo único. Para o efeito da inscrição, é domicílio eleitoral o lugar de residência ou moradia do requerente, e, verificado ter o alistando mais de uma, considerar-se-á domicílio qualquer delas.

${ }^{51}$ Art. 22. Cabe aos índios ou silvícolas a posse permanente das terras que habitam e o direito ao usufruto exclusivo das riquezas naturais e de todas as utilidades naquelas terras existentes.

Parágrafo único. As terras ocupadas pelos índios, nos termos deste artigo, serão bens inalienáveis da União (artigo 4º IV, e 198, da Constituição Federal).

${ }^{52}$ Art. 23. Considera-se posse do índio ou silvícola a ocupação efetiva da terra que, de acordo com os usos, costumes e tradições tribais, detém e onde habita ou exerce atividade indispensável à sua subsistência ou economicamente útil. 
$12^{53}$ e $13^{54}$ do Estatuto do Índio, não garantindo o direito ao alistamento ${ }^{55}$. A questão se torna mais complexa no mesmo artigo do Código Eleitoral, inciso II, que traz a obrigatoriedade da quitação da obrigação militar como condição para o alistamento eleitoral. A matéria foi regulamentada pela Resolução 20.806/200156, no sentido de compreender como obrigatório ao indígena o alistamento militar, algo que pode criar problemas no momento do alistamento, e também colide com o art. 231 da Constituição Federal de $1988^{57}$.

Com o ânimo de fomentar a inclusão de indígenas, em decisão de dezembro de 2011, o Plenário do Tribunal Superior Eleitoral (TSE) garantiu o alistamento eleitoral em caráter facultativo aos índios considerados pelo Estatuto do Índio como isolados e em vias de integração ${ }^{58}$. Segundo a

${ }^{53}$ Art. 12. Os nascimentos e óbitos, e os casamentos civis dos índios não integrados, serão registrados de acordo com a legislação comum, atendidas as peculiaridades de sua condição quanto à qualificação do nome, prenome e filiação.

Parágrafo único. O registro civil será feito a pedido do interessado ou da autoridade administrativa competente.

${ }^{54}$ Art. 13. Haverá livros próprios, no órgão competente de assistência, para o registro administrativo de nascimentos e óbitos dos índios, da cessação de sua incapacidade e dos casamentos contraídos segundo os costumes tribais.

Parágrafo único. O registro administrativo constituirá, quando couber documento hábil para proceder ao registro civil do ato correspondente, admitido, na falta deste, como meio subsidiário de prova.

${ }^{55}$ Cf. FERREIRA, Lara Marina. Estudo preliminar, Eixo temático VII: participação feminina, jovens, negros, indígenas, pessoas com deficiência e presos. Diálogos para a construção da sistematização das normas eleitorais. Brasília: TSE, 2019. p. 12-13. Disponível em: < http://www.tse.jus.br/legislacao/sne/arquivos/gt-vii-eixo-transversal-estudo-preliminar> Acesso em 12 jul. 2019.

${ }^{56}$ Resolução 20.806, de 15 de maio de 2001: "Alistamento eleitoral. Exigências. São aplicáveis aos indígenas integrados, reconhecidos no pleno exercício dos direitos civis, nos termos da legislação especial (Estatuto do Índio), as exigências impostas para o alistamento eleitoral, inclusive de comprovação de quitação do serviço militar ou de cumprimento de prestação alternativa."

${ }^{57}$ Cf. FERREIRA, Lara Marina. Estudo preliminar, Eixo temático VII: participação feminina, jovens, negros, indígenas, pessoas com deficiência e presos. Diálogos para a construção da sistematização das normas eleitorais. Brasília: TSE, 2019. p. 15-16. Disponível em: < http://www.tse.jus.br/legislacao/sne/arquivos/gt-vii-eixo-transversal-estudo-preliminar> Acesso em 12 jul. 2019.

${ }^{58}$ A título de observação, em outra ocasião, no Respe nº 287-84, rel. Min. Henrique Neves, debateu-se se um cacique de aldeia indígena pode ser sujeito ativo na prática de abuso de autoridade, devendo, em caso positivo, figurar em polo passivo de ação de investigação 
decisão, os índios alfabetizados devem se inscrever como eleitores, mas não estão sujeitos ao pagamento de multa pelo atraso no alistamento eleitoral (art. 16 da Resolução n⿳0 21.538/2003) ${ }^{59}$.

Por fim, especificamente no caso da Resolução n. ${ }^{2}$ 23.554/2017 do TSE, nos termos do art. 34, não há menção aos indígenas sobre, nas eleições gerais, a faculdade aos eleitores da transferência temporária de seção eleitoral para votação no primeiro turno, no segundo turno ou em ambos. Não há previsão tampouco para seções eleitorais especiais para indígenas ${ }^{60}$, ainda que é importante mencionar os esforços da Justiça Eleitoral em atuar para instalar essas seções em algumas aldeias de difícil acesso ${ }^{61}$.

Isso demonstra que, em que pesem os esforços da Justiça Eleitoral em incluir e fomentar os direitos políticos dos indígenas, todavia há providências a serem tomadas, devendo-se partir de uma leitura conjunta da

judicial eleitoral. Em seu voto vista, o Min. Luiz Fux argumentou a sua posição desde o ponto de vista do direito à diferença e ao reconhecimento, restando, portanto, impossível de se imputar a prática de abuso de poder de autoridade a ele. Sobre o tema, cf. FUX, Luiz. FRAZÃO, Carlos Eduardo. Novos paradigmas do direito eleitoral. Belo Horizonte: Fórum, 2016. p. 87-104.

59 “[...] Alistamento. Voto. Indígena. Categorização estabelecida em lei especial. 'Isolado'. 'Em vias de integração'. Inexistência. Óbice legal. Caráter facultativo. Possibilidade. Exibição. Documento. Registro Civil de Nascimento ou administrativo da FUNAI. 1. A atual ordem constitucional, ao ampliar o direito à participação política dos cidadãos, restringindo o alistamento somente aos estrangeiros e aos conscritos, enquanto, no serviço militar obrigatório, e o exercício do voto àqueles que tenham suspensos seus direitos políticos, assegurou-os, em caráter facultativo, a todos os indígenas, independentemente da categorização estabelecida na legislação especial infraconstitucional anterior, observadas as exigências de natureza constitucional e eleitoral pertinentes à matéria, como a nacionalidade brasileira e a idade mínima. 2. Os índios que venham a se alfabetizar devem se inscrever como eleitores, não estando sujeitos ao pagamento de multa pelo alistamento extemporâneo, de acordo com a orientação prevista no art. 16, parágrafo único, da Res.-TSE 21.538, de 2003. 3. Para o ato de alistamento, faculta-se aos indígenas que não disponham do documento de registro civil de nascimento a apresentação do congênere administrativo expedido pela Fundação Nacional do Índio (FUNAI).” (Ac. de 6.12.2011 no PA nº 180681, rel. Min. Nancy Andrighi.).

${ }^{60}$ Cf. FERREIRA, Lara Marina. Estudo preliminar, Eixo temático VII: participação feminina, jovens, negros, indígenas, pessoas com deficiência e presos. Diálogos para a construção da sistematização das normas eleitorais. Brasília: TSE, 2019. p. 30-33. Disponível em: < http://www.tse.jus.br/legislacao/sne/arquivos/gt-vii-eixo-transversal-estudo-preliminar> Acesso em 12 jul. 2019.

${ }^{61}$ Cf. <https://g1.globo.com/jornal-nacional/noticia/2018/10/05/sete-aldeias-indigenas-de-mato-grosso-terao-secoes-eleitorais-pela-primeira-vez.ghtml> Acesso em 12 jul. 2019. 
normativa internacional, da Constituição Federal de 1988 e da legislação infraconstitucional, realizando-se inclusive um controle de convencionalidade e de constitucionalidade sobre as normas de níveis inferiores na hierarquia normativa.

Cabe ressaltar que há o Projeto de Lei 2.051/91, que versa sobre o Estatuto dos Povos Indígenas e que visa à reforma da normativa infraconstitucional no que se refere aos direitos indígenas. O texto já trata o índio como um indivíduo com plena capacidade civil, eliminando o paradigma da assimilação do seu regime jurídico ${ }^{62}$.

\section{Algumas conclusões}

Como foi possível observar, existe um conjunto normativo específico na proteção dos direitos indígenas, não ficando os direitos políticos excluídos do espectro de garantia.

Contudo, há lacunas que merecem atenção. Elas, se permanecerem, podem obstruir o direito ao voto de indígenas, bem como o direito a ser votado e de participar dos assuntos públicos. É fato que o número de candidaturas de indígenas vem crescendo. Em 2016, foram 1.715 candidatos que se autodeclararam indígenas, estando a maior parte dos pedidos de registro no norte do país, com 648 índios, seguido pelo nordeste (411), centro-oeste (284), sudeste (208) e sul, com 114 registros de candidatura. Desse total, apenas 173 índios foram eleitos, sendo, portanto, um número pequeno quando comparado à população total no $\mathrm{Brasil}^{63}$.

Em 2018, houve um crescimento de $56,47 \%$ de candidatos que se declararam índios ou descendentes ao realizarem o pedido de registro de candidatura. Foram 133 concorrentes ao pleito, contra 85 nas eleições gerais de 2014. O número de eleitos também saltou de um deputado estadual, em 2014, para uma deputada federal e um vice-presidente da República, em 2018. O general Hamilton Mourão (PRTB) integrou a chapa eleita para presidir o país, e a advogada Joenia Wapichana (REDE) conquistou uma cadeira na Câmara Federal pelo estado de Roraima ${ }^{64}$.

\footnotetext{
${ }^{62} \mathrm{O}$ projeto encontra-se pronto para pauta de plenário desde 2012, na Câmara dos Deputados. ${ }^{63}$ Cf. < http://www.tse.jus.br/imprensa/noticias-tse/2018/Abril/facilitar-o-voto-de-povos-indigenas-e-preocupacao-da-justica-eleitoral> Acesso em 12 jul. 2019.

${ }^{64}$ Cf. < http://www.tse.jus.br/imprensa/noticias-tse/2019/Abril/candidatos-indigenas-aumentam-participacao-em-eleicoes-nacionais> Acesso em 12 jul. 2019.
} 
No entanto, embora se possa comemorar os avanços no tema, há uma pressão constante pela invisibilidade dos indígenas, o que exige também uma contínua postura de garantia dos direitos desses grupos, de forma sempre expansiva. Nesse contexto, os direitos políticos são a base dessa ampla proteção que deve incidir sobre a população autóctone.

\section{Referências}

AGUIAR, Asdrúbal. La democracia en la jurisprudencia de la Corte Interamericana de Derechos Humanos: 1987-2012. In: PÉREZ CORTI, José María (dir.). Memoria del I ${ }^{o}$ Congreso Argentino de Derecho Electoral. Buenos Aires: Infojus, 2012.

AMAYA, Jorge Alejandro. Tensiones entre decisiones de los órganos del Sistema Interamericano de Derechos Humanos y el derecho interno de los Estados en materia de derechos políticos. Lex. n⿳o 18, año XIV, p. 19-33, 2016.

; LOIANNO, Adelina. Derechos Políticos y medidas cautelares de la CIDH: reflexiones e interrogantes del caso 'Gustavo Petro'. Revista Iberoamericana de Derecho Procesal Constitucional. no 21, p. 295-321, ene./ jun. 2014.

ANJOS FILHO, Robério Nunes dos. Breve balanço dos direitos das comunidades indígenas: alguns avanços e obstáculos desde a Constituição de 1988. Revista Brasileira de Estudos Constitucionais - RBEC, Belo Horizonte, ano 2, n. 8, out./dez. 2008. Disponível em: <http://www.bidforum.com.br/ PDI0006.aspx?pdiCntd=56008> Acesso em 12 jul. 2019.

ARAÚJO, Sílvia Dettmer; MORAES, Júlia Thais de Assis. Breve análise entre a Constituição Federal e a institucionalização dos direitos fundamentais no contexto indígena. Revista Aporia Jurídica, [S.l], v. 1, n. 8, p. 228- 240, jul-dez, 2017.

ARTILHEIRO, Marcelo Feliz. Dos direitos eleitorais dos indígenas. Resenha eleitoral - Revista técnica. n. 7, jan./jun. 2015. Disponível em: <http://www. tre-sc.jus.br/site/resenha-eleitoral/revista-tecnica/edicoes/n-7-janjun-2015/ integra/indexf5c5.html?no_cache=1\&tx_news_pi1\%5Bnews $\% 5 \mathrm{D}=9372 \& \mathrm{tx}$ _ news_pi1 $\% 5$ Bmonth $\% 5 \mathrm{D}=J$ une\&tx_news_pi $\% 5 \mathrm{Byear} \% 5 \mathrm{D}=2015 \& \mathrm{cHash}=$ c367f6c8796ea0a1e0035005e2c4de7c> Acesso em 12 jul. 2019.

BALDI, César Augusto; RIBEIRO, Lilian Márcia de Castro. A proposta de revogação da convenção 169 da OIT pelo Brasil e o princípio da vedação do retrocesso social. Fragmentos de Cultura. Goiânia, v. 25, n. 2, p. 241-252, abr./jun. 2015. 
BARBOSA, Marco Antônio. Autodeterminação direito à diferença. São Paulo: Plêiade, 2001. p. 302.

BRAUN, Helenice da Aparecida Dambrós. Efetividade dos direitos trabalhistas dos indígenas e seus instrumentos jurídicos: uma análise das demandas trabalhistas das comunidades indígenas em Chapecó. Florianópolis, 2016. 356 f. Tese (Doutorado em Direito) - Centro de Ciências Jurídicas, pós-graduação em Direito, Universidade Federal de Santa Catarina.

CARVALHO RAMOS, André de. Teoria geral dos direitos humanos na ordem internacional. 6. ed., São Paulo: Saraiva, 2016.

COMPARATO, Fábio Konder. A afirmação histórica dos Direitos Humanos. 10. ed. São Paulo: Saraiva, 2016.

FERREIRA, Lara Marina. Estudo preliminar, Eixo temático VII: participação feminina, jovens, negros, indígenas, pessoas com deficiência e presos. Diálogos para a construção da sistematização das normas eleitorais. Brasília: TSE, 2019. p. 9-10. Disponível em: < http://www.tse.jus.br/legislacao/sne/ arquivos/gt-vii-eixo-transversal-estudo-preliminar> Acesso em 12 jul. 2019.

FUX, Luiz. FRAZÃO, Carlos Eduardo. Novos paradigmas do direito eleitoral. Belo Horizonte: Fórum, 2016. p. 87-104.

MAZZUOLI, Valério de Oliveira. Direitos humanos na jurisprudência internacional. Sentenças, opiniões consultivas, decisões e relatórios internacionais. São Paulo: Método, 2019.

MELO, José Wilson Rodrigues de. Multiculturalismo: tensões brasileiras do direito à diferença como expressão de igualdade e dignidade. Revista ESMAT, [S.1.], v.8, n. 11, p. 91-104, jul./dez. 2017.

NACIONES UNIDAS. Comentarios generales adoptados por el Comité de los Derechos Humanos, Artículo 25 - La participación en los asuntos públicos y el derecho de voto, $57^{\circ}$ período de sesiones, U.N. Doc. HRI/ GEN/1/Rev.7 at 194 (1996). Disponível em: < http://hrlibrary.umn.edu/ hrcommittee/Sgencom25.html> Acesso em 11 jul. 2019.

PRIOTTT, Anahí; TRUCCO, Marcelo. La cláusula democrática en los procesos de integración latinoamericana. RecorDip - Revista electrónica cordobesa de derecho internacional público. v. 2, n. 2, 2012. Disponível em: <https://revistas.unc.edu.ar/index.php/recordip/article/view/3027> Acesso em 11 jul. 2019.

RAMOS, André de Carvalho. Curso de Direitos Humanos. 4. ed. São Paulo: Saraiva, 2017. 
RODRIGUES, Ricardo José Pereira. Democracia e Participação Política dos Povos Indígenas: a questão da representação especial. Interesse Público - IP, Belo Horizonte, ano 16, n. 88, nov./dez. 2014. Disponível em: <http:/ /www. bidforum.com.br/PDI0006.aspx?pdiCntd=230453> Acesso em 12 jul. 2019.

ROULAND, Norbert; PIERRÉ-CAPS, Stephane; POUMARÈDE, Jacques. Droit des minorités et des peuples autochtones. Paris: Presses Universitaires de France, 1996.

SANTANO, Ana Claudia. Observação eleitoral internacional: por que o Brasil não adere a esta ideia? Sugestões para uma maior integração democrática regional. In: MORAES, Filomeno; SALGADO, Eneida Desiree; AIETA, Vânia Siciliano. (Org.). Justiça eleitoral, controle das eleições e soberania popular. Curitiba: Íthala, 2016, v. 1, p. 11-44.

SANTOS, Rodrigo Mioto dos. Pluralismo, multiculturalismo e reconhecimento uma análise constitucional do direito dos povos indígenas ao reconhecimento. Revista da Faculdade de Direito UFPR, [S.I.], v. 43, n. 0, 2005.

SILVA, Ana Paula da; FREIRE, José Ribamar Bessa. As palavras e a letra: Etnosaberes Tupinambá nas fontes coloniais. Disponível em: < http://www. snh2011.anpuh.org/resources/anais/14/1308326908_ARQUIVO_Artigo_ Anpuh_Nacional_2011_Ana_Paula_em06abr11_alterado_Haverroth_ em07abr11.pdf > Acesso em 12 jul. 2019.

SOUZA FILHO, Carlos Frederico Marés. Comentário aos artigos 231 e 232. In: CANOTILHO, J. J. Gomes; MENDES, Gilmar Ferreira; SARLET, Ingo Wolfgang; STRECK, Lenio Luiz. (Coords.). Comentários à Constituição do Brasil. São Paulo: Saraiva/Almedina, 2013. p. 4661-4678.

VERDRUM, Ricardo. Povos indígenas no Brasil: o desafio da autonomia. In: VERDRUM, Ricardo (org.). Povos indígenas Constituições e reformas políticas na América Latina. Brasília: Coronário. 2009.

WEBER, Thadeu. Autonomia, dignidade da pessoa humana e respeito em Kant. In: UTZ, Konrad; et al (coor.). Sujeito e liberdade: investigações a partir do idealismo alemão. Porto Alegre: EdiPUCRS, 2012. p. 14-43.

Ana Claudia Santano - Professora do Programa de Pós-graduação em Direitos Fundamentais e Democracia do Centro Universitário Autônomo do Brasil - UniBrasil. Pós-doutora em Direito Público Econômico pela Pontifícia Universidade Católica do Paraná. Doutora e mestre em Ciências Jurídicas e Políticas pela Universidad de Salamanca, Espanha. Curitiba, Paraná, Brasil. E-mail: anaclaudiasantano@yahoo.com.br. 